\title{
Functional and nutritional status of older adults admitted to a general surgery ward
}

Estado funcional e nutricional em pacientes idosos admitidos num serviço de cirurgia geral Estado funcional y nutricional en pacientes ancianos admitidos en un servicio de cirugía general

Leonel São Romão Preto*; Isabel Fernanda Lopes**; Maria Eugénia Rodrigues Mendes***;

André Filipe Morais Pinto Novo ${ }^{* * * *}$; Ilda Maria Morais Barreira*****

\section{Abstract}

Background: Disease-related functional impairment and malnutrition increase the risk of adverse health outcomes.

Objective: To establish a correlation between functional capacity and nutritional status in patients aged over 65 years who were admitted to a general surgery ward.

Methodology: Descriptive and correlational study with a quantitative approach. The sample was composed of 89 older adults (78,0 \pm 6,9 years) admitted to a general surgery ward. Participants were selected using the convenience sampling technique. The research protocol was approved by the Ethics Committee. Patients' functional capacity was assessed using the Barthel Index (BI) and the Lawton and Brody Scale (LBS), and the nutritional status was assessed using the Mini Nutritional Assessment Short-Form (MNA-SF).

Results: The prevalence of malnutrition was $16.9 \%$. Both BI and LBS scores showed a positive correlation with the MNA-SF scores $(R=0.400, p<0.01$ vs $R=0.267, p<0.05)$. The oldest inpatients had lower BI, LBS, and MNA-SF scores $(p<0.01)$. Inpatients with a better functional and nutritional status had greater grip strength in the dominant hand $(p<0.01)$.

Conclusion: Based on the association found between functional capacity and nutritional status, it is recommended to screen surgical patients for these conditions.

Keywords: aged; hospitalization; general surgery; personal autonomy; nutritional status

\section{Resumo}

Enquadramento: $\mathrm{O}$ comprometimento funcional e a desnutrição associada à doença aumentam o risco de resultados adversos em saúde.

Objetivo: Correlacionar a capacidade funcional com o estado nutricional em pacientes com mais de 65 anos admitidos num serviço de cirurgia.

Metodologia: Estudo descritivo e correlacional com abordagem quantitativa, que avaliou, por amostragem de conveniência e protocolo de investigação aprovado por Comissão de Ética, 89 idosos (78,0 \pm 6,9 anos) hospitalizados num serviço de cirurgia. A funcionalidade foi avaliada pelo Indice de Barthel (IB) e Escala Lawton e Brody (ELB) e o estado nutricional pelo Mini Nutritional Assessment Short-Form (MNA-SF).

Resultados: A prevalência de desnutrição foi de 16,9\%. As pontuaçóes obtidas no IB e ELB correlacionaram-se de forma positiva com os valores do MNA-SF $(R=$ $0,400 ; p<0,01$ vs $R=0,267 ; p<0,05)$. Pacientes mais idosos apresentavam menores pontuaçóes no IB, ELB e MNA-SF $(p<0,01)$. Quanto maior a força de preensão da mão dominante, melhor o estado funcional e nutricional $(p<0,01)$.

Conclusáo: A relaçáo encontrada entre funcionalidade e estado nutricional recomenda a triagem destas condiçôes no paciente cirúrgico.

Palavras-chave: idoso; hospitalização; cirurgia geral; autonomia pessoal; estado nutricional

*Ph.D., Coordinating Professor, School of Health, Polvtechnic Institute of Bragança, 5300121, Bragança, Portugal [leonelpreto@ipb.pt].Contribution to the article: Methodologica supervision and article writing. Address for correspondence: Vale Chorido. Rua Senhor do Perdidos, Lote 101, 5300-121 Bragança, Portugal.

**MSc., RN, General Surgery Ward, Mirandela Hospital Unit, 5370-429, Mirandela, Portugal [isabelalope@hotmail.com].Contribution to the article: Data collection and literature search. ***MSc., Adjunct Professor, Nursing Sciences Department, School of Health, Polytechnic Institute of Bragança, 5300-121, Bragança, Portugal [maria.mendes@ipb.pt]. Contribution to the article: Data processing and statistical evaluation.

****Ph.D., Adjunct Professor, School of Health, Polvtechnic Institute of Braganca, 5300-12 Bragança, Portugal [andre@ipb.pt].Contribution to the article: Literature search and article revision

revision.
*****MSc, RN, General Surgery Ward, Mirandela Hospital Unit, 5370-429, Mirandela, Portugal [ildabarreira25@gmail.com].Contribution to the article: Literature search and article revision.

\section{Resumen}

Marco contextual: El compromiso funcional y la desnutrición asociada a la enfermedad aumentan el riesgo de resultados adversos en la salud.

Objetivo: Correlacionar la capacidad funcional con el estado nutricional en pacientes de más de 65 años admitidos en un servicio de cirugía.

Metodología: Estudio descriptivo y correlacional con enfoque cuantitativo en el que se evaluó, por muestreo de conveniencia y protocolo de investigación aprobado por la Comisión de Ética, 89 ancianos (78,0 \pm 6,9 años) hospitalizados en un servicio de cirugía. La funcionalidad se evaluó mediante el Índice de Barthel (IB) y la Escala de Lawton y Brody (ELB), y el estado nutricional por la Mini Nutritional Assessment Short-Form (MNA-SF).

Resultados: La prevalencia de desnutrición fue del $16,9 \%$. Las puntuaciones obtenidas en el IB y la ELB se correlacionaron positivamente con los valores de la MNA-SF $(R=0,400 ; p<0,01$ vs $\mathrm{R}=0,267 ; p<0,05)$. Los pacientes más mayores presentaron menores puntuaciones en el IB, la ELB y la MNA-SF $(p<0,01)$. Cuanto mayor es la fuerza de agarre de la mano dominante, mejor es el estado funcional y nutricional $(p$ $<0,01)$.

Conclusión: Debido a la relación que se encontró entre funcionalidad y estado nutricional, se recomienda clasificar estas condiciones en el paciente quirúrgico.

Palabras clave: anciano; hospitalización; cirugía general; autonomía personal; estado nutricional 


\section{Introduction}

Hospitalization rates are higher among people aged over 65 years as a result of the increasing aging of the population (Brinson, Tang, \& Finlayson, 2016). In this age group, disease and hospitalization accelerate both functional and cognitive decline (Mendes, Rodrigues, Novo, Preto, \& Novo, 2016) which, in turn, influence the length of hospital stay and other health-related outcomes. Previous studies suggest that postoperative mortality increases progressively when associated with old age and preoperative functional disability, particularly in geriatric surgical patients (Robinson et al., 2009). A poor functional status reduces the quality of life and increases the risk for postoperative complications and institutionalization (Brinson et al., 2016).

Geriatric surgical patients' characteristics justify the need for a multidimensional assessment upon admission, or as soon as possible, in order to diagnose, minimize, and/or prevent impairment (Brinson et al., 2016; Robinson et al., 2009).

Nutritional status is one of the factors that should be screened, as highlighted throughout this study. Patients admitted to general surgery wards often have pathophysiological conditions in the abdominal and pelvic cavities, which cover important organs and systems for the digestion, absorption, and elimination of nutrients. Therefore, the first step to prevent or manage malnutrition in these patients is the evaluation of their nutritional status, which should integrate the clinical routine of the first 24 to 48 hours of admission to the general surgery ward. Studies show a great number of cases of primary or secondary malnutrition at these wards (Barker, Gout, \& Crowe, 2011; Leandro-Merhi et al., 2000).

The prevalence of malnutrition in hospital settings ranges between 20 and 50\%, depending on the population studied and the criteria used for its diagnosis (Barker et al., 2011).

As regards the topic under analysis, it should be noted that surgical patients' adverse outcomes for disease-related malnutrition are similar to those for functional disability, namely: immune system depression, impaired wound healing, muscle wasting, longer length of hospital stay, higher treatment costs, and increased mortality (Barker et al., 2011).

This study aimed to assess the functional capacity and nutritional status of patients aged over
65 years who were admitted to a general surgery ward, as well as to establish a correlation between both variables.

\section{Background}

Functional capacity is defined as the ability to live independently by performing tasks and activities of daily living (Souza, Papini, \& Corrente, 2015). Self-care deficit is influenced by intrinsic factors, such as age, and multiple extrinsic factors, which include, for the purposes of this study, diseases that require hospitalization and surgical intervention. The decline in functional capacity is mostly associated with lower food intake and decreased muscle mass and strength (Fried et al., 2001; Souza et al., 2015). Thus, impaired functional capacity may be an indicator of nutritional risk (Dehghankar, Shahrokhi, Oveisi, Esmailzadehha, \& Ghorbani, 2016), particularly among older inpatients since hospitalization aggravates functional and cognitive decline (Mendes et al., 2016).

Souza et al. (2015) concluded that older people's independence to perform basic and instrumental activities of daily living was associated with a healthy weight. Similarly, Tramontano et al. (2016) reported that the physical performance and functional status of older people were significantly associated with their nutritional status. In a study conducted with 230 older adults who had been recently hospitalized, Abd-Al-Atty, Abou-Hashem, and Elaziz (2012) reported that the nutritional status, which was assessed using the Mini Nutritional Assessment - Short Form (MNA-SF) and biochemical markers, was an important risk factor for the decline in the functional capacity to perform both activities of daily living (ADL) and instrumental activities of daily living (IADL).

Epidemiological studies have reported a malnutrition prevalence in hospital settings of 20 to $50 \%$ (Barker et al., 2011). Given this high prevalence rate, the best therapeutic approach is the identification of patients at risk. Nutritional risk screening enables the diagnosis of nutritional problems which may require a more comprehensive specialized assessment. According to Barker et al. (2011), since it consists of a simple set of questions, it can be performed by the nursing team who will then refer at-risk 
patients to a nutritionist for further assessment. Many patients who are hospitalized for medical-surgical reasons have a history of weight loss caused by anorexia and changes in body reserves that are associated with the disease process. In addition, malnutrition has a negative impact on surgical patients' clinical outcomes because it may increase postoperative complication rates and delay wound healing (Barker et al., 2011). The most common methods used for nutritional diagnosis are the following: measuring anthropometric parameters, such as weight, height, body mass index (BMI), circumferences, and skinfolds; using specific screening tools, such as the MNA-SF; and evaluating biochemical parameters, such as albumin and hematocrit levels (Garcia, Meireles, Fuhr, Donini, \& Wazlawik, 2013; Kaiser et al., 2009).Grip strength testing has also been increasingly used to assess the patient's overall nutritional and functional status, since it is a strong predictor of sarcopenia (Fried et al., 2001; Garcia et al., 2013; Silveira, Sousa, Stringhini, Freitas, \& Melo, 2014).

\section{Research questions}

What is the association between the functional and the nutritional status of older adults admitted to a surgery ward?

Does age correlate with the scores obtained in the Barthel Index (BI), the Lawton and Brody Scale (LBS), and the MNA-SF?

Does the BMI correlate with the scores obtained in the BI, the LBS, and the MNA-SF? Does grip strength correlate with the functional and the nutritional status?

\section{Methodology}

This study is a descriptive and correlational study, using a quantitative approach.

The target population consisted of patients aged over 65 years who were admitted to the General Surgery Ward of the Mirandela Hospital Unit of the Northeast Local Health Unit (Unidade Local de Saúde do Nordeste, ULSNE) for a period of 6 months. Given the impossibility of assessing the total number of patients consecutively admitted to the ward within 24 hours after admission, a convenience sampling technique was used. Thus, the sample was composed of patients who were admitted to the ward during the working schedule of the researcher responsible for the fieldwork and met the inclusion and exclusion criteria.

The following inclusion criteria were applied: patients aged 65 years or older, who were fully conscious (Glasgow Coma Scale $=15$ points), and who gave their informed consent to participate in the study.

The following exclusion criteria were applied: severe or moderate pain, assessed through the numeric pain rating scale used at the ward; ear temperature above $38^{\circ} \mathrm{C}$; self-reported balance difficulties and/or inability to walk; bladder catheterization, nasogastric tube, and/or cardiac monitoring. Patients who had a peripheral venous catheter inserted in the back of the dominant hand were also excluded.

Data were collected by the same researcher using a questionnaire and anthropometric measurement in order to minimize errors. The following variables were analyzed in this study: sociodemographic variables (age, gender, marital status, academic qualifications, and professional situation), clinical variables (main diagnosis), anthropometric variables (weight, height, BMI, and grip strength), as well as variables related to the functional and nutritional status.

After measuring their weight, height, and BMI, participants were distributed according to the criteria proposed by Lipschitz (1994) to screen for nutritional status in the elderly, using the following cutoff values: underweight if $\mathrm{BMI}<22$ $\mathrm{kg} / \mathrm{m}^{2}$; eutrophia if BMI $22 \mathrm{~kg} / \mathrm{m}^{2}$ to $27 \mathrm{~kg} / \mathrm{m}^{2}$; and overweight if BMI $>27 \mathrm{~kg} / \mathrm{m}^{2}$.

The ability to perform ADL was assessed using a 10-item version of the BI with the following activities: feeding, wheelchairs or bed transfers, personal toilet, toilet transfers, bathing self, walking, ascending and descending stairs, dressing and undressing, bowel control, and bladder control. The total score ranges from 0 to 100 points, where the minimum score corresponds to total dependence and the maximum to total independence. Patients were classified based on the following cutoff values: 0 to $20=$ total dependence; 21 to 60 = severe dependence; 61 to 90 = moderate dependence; 91 to $99=$ slight dependence; and $100=$ total independence (Azeredo \& Matos, 2003).

The ability to perform IADL was assessed 
using the eight instrumental activities in the LBS: ability to use telephone, shopping, food preparation, housekeeping, laundry, mode of transportation, responsibility for own medication, and ability to handle finances. Each task is scored based on the ability to perform it. In the version used in this study, each item was scored between 0 and 2, where 0 corresponds to unable, 1 to needs assistance, and 2 to independent. The following qualitative categories were established: $0-5=$ Severe or total dependence; $6-11=$ Moderate dependence; 12-16 = Mild dependence or independence (Araújo, Pais-Ribeiro, Oliveira, Pinto, \& Martins, 2008).

Patients' nutritional status was assessed using the MNA-SF to score items such as loss of appetite, swallowing difficulties, weight loss during the last 3 months, mobility, psychological status, neuropsychological problems, and BMI. Individuals with higher total scores have better nutritional status. Screening scores range from 0 to 14 points, where a score of 0 to 7 means malnourished, 8 to 11 means at risk of malnutrition, and 12 to 14 means well-nourished (Kaiser et al., 2009).

Grip strength in the dominant hand was measured in kilograms-force (Kgf) using a Jamar ${ }^{\odot}$ hand-held dynamometer, with the patient sitting and flexing the forearm at a $90^{\circ}$ angle, based on the average result of three measures with a one-minute interval (Fried et al., 2001). This study was approved by the Ethics Committee and authorized by the Board of Directors of the ULSNE. The sampled older adults agreed to participate voluntarily in the study and signed an informed consent form.

Data were analyzed using the classical statistical methods of descriptive and inferential statistics, using IBM SPSS Statistics, version 22.0. Given the size of the sample, non-parametric tests were performed, namely Spearman's rank correlation coefficient, thus avoiding the need for normality tests. With regard to the variables whose data could be quantitative or measured on an ordinal scale, such as BMI, BI, LBS, and MNA-SF, correlations were analyzed using the quantitative data. A two-tailed $p$-value of $<0.05$ was considered statistically significant.

\section{Results}

With regard to the sociodemographic characterization of the sample, Table 1 shows that the sample was gender-balanced, with 44 women and 45 men. Most participants were married or co-habiting $(50.60 \%)$, retired $(92.10 \%)$, and had only attended basic education $(91.01 \%)$. The participants' mean age was 78 years.

\section{Table 1}

Sociodemographic characterization of the sample

\begin{tabular}{|c|c|}
\hline Variables & $\begin{array}{l}\text { Sample } \\
(n=89)\end{array}$ \\
\hline Age (years), $M \pm S D$ & $78.0 \pm 6.9$ \\
\hline \multicolumn{2}{|l|}{ Gender, $n(\%)$} \\
\hline Female & $44(49.40)$ \\
\hline Male & $45(50.60)$ \\
\hline \multicolumn{2}{|l|}{ Marital status, $n(\%)$} \\
\hline Single & $5(5.60)$ \\
\hline Married/Co-habiting & $45(50.60)$ \\
\hline Divorced/Separated & $4(4.50)$ \\
\hline Widowed & $35(39.30)$ \\
\hline \multicolumn{2}{|c|}{ Academic qualifications, $n(\%)$} \\
\hline Illiterate & $4(4.49)$ \\
\hline Basic education & $81(91.01)$ \\
\hline $6^{\text {th }}$-grade & $2(2.25)$ \\
\hline
\end{tabular}




\begin{tabular}{lc}
\hline Higher education & $2(2.25)$ \\
Professional situation, $n(\%)$ & $7(7.90)$ \\
Active & $82(92.10)$ \\
Retired & \\
\hline
\end{tabular}

Note. $M=$ Mean; $S D=$ Standard deviation.

Table 2 lists the main clinical diagnoses leading to hospitalization. The most prevalent diagnoses were gallbladder and bile duct disorders $(30.3 \%)$, followed by acute pancre- atitis (15.7\%) and colon, sigmoid, or rectal neoplasms $(9.0 \%)$. It should be noted that $15.7 \%$ of patients were admitted for further evaluation.

Table 2

Main clinical diagnoses leading to hospitalization

\begin{tabular}{lc}
\hline & $n(\%)$ \\
\hline Cholecystitis and cholangitis & $27(30.3)$ \\
Acute pancreatitis & $14(15.7)$ \\
Further evaluation & $14(15.7)$ \\
Colon, sigmoid, or rectal neoplasms & $8(9.0)$ \\
Polyps or lesions in the colon and sigmoid & $6(6.7)$ \\
Lower limb injuries & $5(5.6)$ \\
Acute diverticulitis & $4(4.5)$ \\
Gastrointestinal bleeding & $3(3.4)$ \\
Esophageal stenosis & $2(2.3)$ \\
Liver abscess & $2(2.3)$ \\
Gastric neoplasm & $2(2.3)$ \\
Pancreatic neoplasm & $1(1.1)$ \\
Burns & $1(1.1)$ \\
TOTAL & $89(100.0)$ \\
\hline
\end{tabular}

The mean score of functional independence to perform ADL was 88.9 in the BI. Based on this score, most patients $(55.1 \%)$ were rated as independent in ADL, while only $36.0 \%$ were independent in IADL (Table 3 ).

Regarding their nutritional status, $16.9 \%$ of the patients were malnourished, $57.3 \%$ were at risk of malnutrition, and $25.8 \%$ were well-nourished (Table 3).
The participants had a mean weight of $68.1 \mathrm{Kg}$ and a mean height of $1.64 \mathrm{~m}$, resulting in a mean BMI of $25.3 \mathrm{Kg} / \mathrm{m}^{2}$. Patient were distributed according to the cutoff values as follows: 29 of them (32.6\%) were underweight, 33 (37.1\%) were euthrophic, and 27 (30.3\%) were overweight (Table 3).

The mean score for grip strength in the dominant hand was $20.7 \mathrm{Kgf}$. 
Table 3

Descriptive statistics, anthropometric measures, and patient distribution according to the variables related to the functional and the nutritional status

\begin{tabular}{|c|c|}
\hline Variables & Sample $(n=89)$ \\
\hline Barthel Index, $M \pm S D$ & $88.9 \pm 15.2$ \\
\hline \multicolumn{2}{|l|}{ BI categories, $n(\%)$} \\
\hline Total dependence & $0(0.0)$ \\
\hline Severe dependence & $7(7.9)$ \\
\hline Moderate dependence & $27(30.3)$ \\
\hline Mild dependence & $6(6.7)$ \\
\hline Total independence & $49(55.1)$ \\
\hline Lawton and Brody Scale, $M \pm S D$ & $10.2 \pm 4.0$ \\
\hline \multicolumn{2}{|l|}{ LBS categories, $n(\%)$} \\
\hline Severe or total dependence & $13(14.6)$ \\
\hline Moderate dependence & $44(49.4)$ \\
\hline Mild dependence or independence & $32(36.0)$ \\
\hline Mini Nutritional Assessment Short-Form, $M \pm S D$ & $10.2 \pm 4.0$ \\
\hline \multicolumn{2}{|l|}{ MNA-SF categories, $n(\%)$} \\
\hline Malnourished & $15(16.9)$ \\
\hline At risk of malnutrition & $51(57.3)$ \\
\hline Well-nourished & $23(25.8)$ \\
\hline Weight $(\mathrm{Kg}), M \pm S D$ & $68.1 \pm 15.6$ \\
\hline Height (m), $M \pm S D$ & $1.64 \pm 0.11$ \\
\hline Body Mass Index $\left(\mathrm{kg} / \mathrm{m}^{2}\right), M \pm S D$ & $25.3 \pm 5.2$ \\
\hline \multicolumn{2}{|l|}{ BMI categories, $n(\%)$} \\
\hline Underweight & $29(32.6)$ \\
\hline Eutrophic & $33(37.1)$ \\
\hline Overweight & $27(30.3)$ \\
\hline Obese & $0(0.0)$ \\
\hline Grip strength $(\mathrm{Kgf}), M \pm S D$ & $20.7 \pm 9.8$ \\
\hline
\end{tabular}

Note. $\mathrm{BI}=$ Barthel Index; $M=$ Mean; $S D=$ Standard deviation; LBS = Lawton and Brody Scale; MNA-SF = Mini Nutritional Assessment Short-Form; BMI = Body Mass Index; Kgf = Kilogram-force.

Table 4 shows the correlations found between functionality scores (BI and LBS) and MNA-SF scores, among others. There is a positive and statistically significant correlation between $\mathrm{BI}$ and MNA-SF scores $(R=0.400 ; p<0.01)$, which means that patients who are more independent in the performance of ADL have better nutritional status. A similar correlation was found between instrumental independence, as assessed by the LBS, and nutritional status, as assessed by the MNA-SF $(R=0.267 ; p<0.05)$.

Age was strongly correlated with the BI scores
$(R=-0.716 ; p<0.01)$ and moderately correlated with the LBS scores $(R=-0.614 ; p<0.01)$. These variables are negatively correlated, which suggests that younger patients have higher functional independence (Table 4).

BMI was moderately and positively correlated with nutritional status $(R=0.532 ; p<0.01)$.

Grip strength decreased with age $(R=-0.557 ; p<$ $0.01)$. In addition, it showed a moderate positive correlation with independence in the performance of $\mathrm{ADL}(R=0.531 ; p<0.01)$ and a weak correlation with nutritional status $(R=0.465 ; p<0.01)$. 
Table 4

Spearman's correlations between functional status (BI, LBS), nutritional status (MNA-SF), and other sociodemographic and anthropometric variables

\begin{tabular}{lllllll}
\hline & $B I$ & $L B S$ & $M N A-S F$ & Age & BMI & $G S$ \\
\hline$B I$ & 1 & & & & & \\
LBS & $0.760^{* *}$ & 1 & & & & \\
MNA-SF & $0.400^{* *}$ & $0.267^{*}$ & 1 & & & \\
Age & $-0.716^{* *}$ & $-0.614^{* *}$ & $-0.332^{* *}$ & 1 & & \\
BMI & $0.293^{* *}$ & $0.287^{* *}$ & $0.532^{* *}$ & $-0.277^{* *}$ & 1 & \\
GS & $0.531^{* *}$ & $0.266^{*}$ & $0.465^{* *}$ & $-0.557^{* *}$ & $0.350^{* *}$ & 1 \\
\hline
\end{tabular}

Note. BI = Barthel Index; LBS $=$ Lawton and Brody Scale; MNA-SF $=$ Mini Nutritional Assessment Short-Form; BMI = Body Mass Index; GS = Grip Strength; ${ }^{*} p<0.05 ;{ }^{* *} p<0.01$.

\section{Discussion}

One of the objectives of this study was to assess surgical patients' functional independence in ADL and IADL and establish a correlation between this performance and their nutritional status.

Results showed greater functional dependence in IADL, which may be explained by the fact that IADL require more physical and cognitive abilities. These activities are the first domain to be affected by functional decline, followed by self-care activities (Merino Martín $\&$ Cruz-Jentoft, 2012). When associated with aging, disease-related physiological changes trigger a cascade to dependency that often begins before hospital admission and worsens during the hospital stay, leading to poor outcomes at discharge and after discharge (Merino Martín \& Cruz-Jentoft, 2012; Mendes et al., 2016). These results show the importance of assessing older inpatients' functional status to allow for the early implementation of adequate rehabilitation programs. Screening has become imperative because, although the technological and scientific advances ensure the perioperative safety of increasingly older patients, these patients are at a higher risk of poor functional outcomes after discharge (Brinson et al., 2016).

In this study, $16.9 \%$ of the older people were malnourished and $57.3 \%$ were at risk of malnutrition. In an integrative review, Barker et al. (2011) found a prevalence of malnutrition ranging from $20 \%$ to $50 \%$ among hospitalized adult patients. In addition, a recent systematic review conducted by Correia, Perman, and Waitzberg (2017) pointed to a high prevalence of malnutrition among patients undergoing abdominal surgery $(61.5 \%)$, colon surgery (63.6\%), and hernia surgery (55\%).

Previous studies suggest that older people's nutritional status influences their functional capacity (Abd-Al-Atty et al., 2012; Tramontano et al., 2016). In this study, the MNA-SF scores had a greater statistically significant correlation with the BI scores than with the LBS scores. The positive correlations between these scores suggest that difficulties in performing selfcare activities, such as food preparation, have a negative impact on nutritional status. They also suggest that fatigue and sarcopenia caused by malnutrition have a negative impact on the physical capacity to perform ADL, in what can be considered a vicious cycle, similar to the cycle of frailty in older adults that is described in the literature (Fried et al., 2001).

In line with other studies (Brinson et al., 2016; Merino Martín \& Cruz-Jentoft, 2012), functional dependence in both ADL and IADL increases with age. In general, older patients tend to be hospitalized for longer periods, are more likely to be institutionalized, and have a lower functional capacity 3 months after discharge (Merino Martín \& Cruz-Jentoft, 2012).

In this study, the BMI of older people was mostly correlated with the MNA-SF scores, which may be explained by the decrease in muscle and fat mass resulting from disease-related unintentional weight loss. 
Regarding the fourth research question, grip strength was mostly correlated with the BI and MNA-SF scores. As an indicator for overall functional capacity, decreased grip strength has been associated with sarcopenia, frailty, and malnutrition in older people. It has been used to detect functional risk after medical-surgical conditions (Fried et al., 2001; Turusheva, Frolova, \& Degryse, 2017).

A recent study with 611 community-dwelling older people found a strong association between low grip strength and nutritional risk, as assessed by the MNA-SF, as well as a strong correlation between grip strength and unintentional weight loss of $6 \mathrm{~kg}$ over the past 6 months (or $3 \mathrm{~kg}$ over the past 3 months) and a weak correlation between grip strength and BMI (Turusheva et al., 2017). People with decreased strength are expected to be physically more inactive and more vulnerable to functional decline and malnutrition (Turusheva et al., 2017). A study conducted in hospital settings concluded that malnourished patients had, on average, lower grip strength (less $11 \mathrm{Kgf}$ ) than well-nourished patients (Garcia et al., 2013).

This study had some limitations due to the fact that it was a cross-sectional, single-center study which was conducted using a non-probability sampling technique. However, its results and the current state-of-the-art on the topic suggest that surgical diseases are associated with functional decline, lower food intake, and malnutrition in what appears to be a vicious cycle that, given the increasing number of hospitalized older people, health professionals should not underestimate in their clinical practice (Brinson et al., 2016).

In a systematic review on the barriers and facilitators to nutritional screening on admission, Green and James (2013) concluded that the organizational culture, the lack of time, the trust in clinical judgment over screening tools, and the lack of practice and training are the main barriers. On the other hand, the continued use of screening tools in clinical practice increases professionals' proficiency in nutritional screening (Green \& James, 2013).

\section{Conclusion}

Epidemiological studies have shown that older people are more vulnerable to diseases and more likely to be hospitalized. In addition, technological advances, particularly in surgical and anesthetic techniques, increase the possibilities for elective and urgent surgeries, which leads to an increase in the number of hospitalized older people.

Hospitalization is a risk factor for functional decline; therefore, it is of utmost importance, both for clinical practice and research, to understand the trajectory of functional capacity among hospitalized patients. The results of this study indicate that the functional decline and malnutrition observed in older people at hospital admission can also be found in surgical patients and that the variables are strongly correlated. Given its association with functional and nutritional status, grip strength should not be undervalued in geriatric clinical practice and research. With regard to research, further studies should be conducted to add sarcopenia screening and the measurement of whole-body and segmental muscle volume to the set of variables proposed in this study for the evaluation of surgical patients.

The results of this study emphasize the importance of integrating into nursing care the routine functional and nutritional screening of older patients at hospital admission. Nutritional risk screening, using the MNA-SF and the traditional anthropometric and biochemical parameters, is of utmost importance because it allows for the early diagnosis of patients' nutritional status which, in turn, facilitates the timely treatment of malnutrition. Nurses play a key role in identifying patients at risk and managing their nutritional status.

\section{References}

Abd-Al-Atty, M. F., Abou-Hashem, R. M., \& Elaziz, K. A. (2012). Functional capacity of recently hospitalized elderly in relation to nutritional status. European Geriatric Medicine, 3(6), 356-359.

Araújo, F., Pais-Ribeiro, J., Oliveira, A., Pinto, C., \& Martins, T. (2008). Validação da escala de Lawton e Brody numa amostra de idosos não institucionalizados. In Leal, J., Pais-Ribeiro, J., Silva, I. \& Marques, S. Intervenção em psicologia e saúde: actas do $7^{\circ}$ congresso nacional de psicologia da saúde. Lisboa: ISPA (pp. 217-22).

Azeredo, Z., \& Matos, E. (2003). Grau de Dependên- 
cia em Doentes que sofreram AVC. Revista da Faculdade de Medicina de Lisboa, 8(4), 199-204.

Barker, L. A., Gout, B. S., \& Crowe, T. C. (2011). Hospital malnutrition: prevalence, identification and impact on patients and the healthcare system. International Journal of Environmental Research and Public Health, 8(2), 514-527. doi:10.3390/ ijerph8020514

Brinson, Z., Tang, V. L., \& Finlayson, E. (2016). Postoperative functional outcomes in older adults. Current Surgery Reports, 4(6). doi:10.1007/s40137016-0140-7

Correia, M. I. T. D., Perman, M. I., \& Waitzberg, D. L. (2017). Hospital malnutrition in Latin America: A systematic review. Clinical Nutrition, 36(4), 958967. doi:10.1016/j.clnu.2016.06.025

Dehghankar, L., Shahrokhi, A., Oveisi, S., Esmailzadehha, N., \& Ghorbani, A. (2016). Impact of functional capacity on nutritional status of hospitalized elderly in Qazvin, Iran. Biotechnology and Health Science, 3(1), e34470.

Fried, L. P., Tangen, C. M., Walston, J., Newman, A. B., Hirsch, C., Gottdiener, J., . . . Group, C. H. S. C. R. (2001). Frailty in older adults: evidence for a phenotype. The journals of gerontology. Series A, Biological sciences and medical sciences, 56(3), M146-156.

Garcia, M. F., Meireles, M. S., Führ, L. M., Donini, A. B., \& Wazlawik, E. (2013). Relationship between hand grip strength and nutritional assessment methods used of hospitalized patients. Revista de Nutrição, 26(1), 49-57.

Green, S. M., \& James, E. P. (2013). Barriers and facilitators to undertaking nutritional screening of patients: a systematic review. J Hum Nutr Diet, 26(3), 211-221. doi:10.1111/jhn.12011

Kaiser, M. J., Bauer, J. M., Ramsch, C., Uter, W., Guigoz, Y., Cederholm, T., . . Group, M.-I. (2009). Validation of the Mini Nutritional Assessment Short-Form (MNA-SF): a practical tool for identification of nutritional status. The Journal of Nutrition, Health and Aging, 13(9), 782-788.
Leandro-Merhi, V., Diez Garcia, R. W., Tafner, B., Florentino, M. C., Casteli, R., \& Aquino, J. L. B. (2000). Relação entre o estado nutricional e as características clínicas de pacientes internados em enfermaria de cirurgia. Revista de Ciências Médicas, 9(3), 105-114.

Lipschitz, D. A. (1994). Screening for nutritional status in the elderly. Primary Care, 21(1), 55-67.

Merino Martín, S., \& Cruz-Jentoft, A. (2012). Impact of hospital admission on functional and cognitive measures in older subjects. European Geriatric Medicine, 3(4), 208-212.

Mendes, E., Rodrigues, J., Novo, A., Preto, L., \& Novo, A. (2016). Functional and cognitive decline in hospitalized elderly. Aging \& Innovation, 5(3), 11-21.

Robinson, T. N., Eiseman, B., Wallace, J. I., Church, S. D., McFann, K. K., Pfister, S. M., . . . Moss, M. (2009). Redefining geriatric preoperative assessment using frailty, disability and co-morbidity. Annals of Surgery, 250(3), 449-455. doi:10.1097/ SLA.0b013e3181b45598

Silveira, T. M., Sousa, J. B., Stringhini, M. L., Freitas, A. T., \& Melo, P. G. (2014). Nutritional assessment and hand grip strength of candidates for surgery of the gastrointestinal tract. Arquivos Brasileiros de Cirurgia Digestiva, 27(2), 104-108.

Souza, L. B., Papini, S. J., \& Corrente, J. E. (2015). Relationship between Nutritional Status and Functional Capacity for Older People. Health, 7, 10901097.

Tramontano, A., Veronese, N., Giantin, V., Manzato, E., Rodriguez-Hurtado, D., Trevisan, C., . . Sergi, G. (2016). Nutritional status, physical performance and disability in the elderly of the Peruvian Andes. Aging Clinical and Experimental Research, 28(6), 1195-1201. doi:10.1007/s40520-016-0591-9

Turusheva, A., Frolova, E., \& Degryse, J. M. (2017). Age-related normative values for handgrip strength and grip strength's usefulness as a predictor of mortality and both cognitive and physical decline in older adults in northwest Russia. Journal of Musculoskeletal and Neuronal Interactions, 17(1), 417-432. 
